\title{
NON-INFRINGING USES IN DIGITAL SAMPLING: THE ROLE OF FAIR USE AND THE DE MINIMIS THRESHOLD IN SAMPLE Clearance Reform ${ }^{*}$
}

\section{KEMBREW MCLEOD ${ }^{* *}$}

\section{Peter DiCola ${ }^{* * \star}$}

In this book excerpt, the authors address the role of two major legal exceptions to copyright protection in the music industry's practices surrounding digital sampling. Although the United States law on the books requires a balance between the interests of copyright owners and sampling musicians, the business practice has been to mandate licensing in almost every instance. Despite this hurdle to a more balanced approach to sampling, the authors discuss several benefits that might come through doctrinal or statutory reforms, or even through developing best practices for claiming fair use.

Digital sampling is the widespread practice of using existing music in the creation of a new piece of music. In the terminology of copyright law, sampling means incorporating portions of existing sound recordings (and, by implication, portions of their underlying compositions) into a new sound recording (and its composition). Thus, using a sample might constitute copyright infringement of two different works. The ultimate legal conclusion on infringement will depend on the extent of copyright owners' rights, the availability of various defences to sampling musicians, and the specific facts of each instance of sampling. But the business practice that has emerged in the shadow of copyright law is equally important, as we argue in our book, Creative License: The Law and Culture of Digital Sampling. ${ }^{1}$ We interviewed over 100 musicians, lawyers, executives,

\footnotetext{
* This article was excerpted, with the permission of the publisher, and adapted from Kembrew McLeod and Peter DiCola, Creative License: The Law and Culture of Digital Sampling (Duke University Press, 2011) 222-33.

** BS (Sociology, James Madison University), MY (Sociology, University of Virginia), PhD (Communication, University of Massachusetts-Amhert); Associate Professor, Department of Communications Studies, University of Iowa, United States.

*** AB (Princeton University), JD (University of Michigan), PhD (Economics, University of Michigan); Associate Professor, Northwestern University School of Law, United States.

${ }^{1}$ Kembrew McLeod and Peter DiCola, Creative License: The Law and Culture of Digital Sampling (Duke University Press, 2011).
} 
and expert commentators to document the current music-industry process for obtaining licences to use samples. This process, known as the sample clearance system (to get a licence for a sample is to "clear" it), suffers from various inefficiencies and inequities, which we document in detail in the book. We argue that the hurdles to clearing samples have significant and often detrimental effects on musical creativity and the ability to disseminate creative works commercially to a wide audience.

No single reform can fix the deficiencies in sample licensing. Only a set of complementary reforms that change both copyright law and business practices can address all its shortcomings - which is no small feat. A multifaceted approach also responds to the wide variety of scenarios in which one musician samples another. Practically speaking, the best solutions are systems that artists and other music-industry groups would voluntarily embrace. Incremental change may be preferable to sweeping legislative change, and some parts of the current sample clearance system may already reflect a reasonable balancing of the competing interests involved in sampling. Moreover, most legislatures which would need to instigate any changes in copyright law - probably lack the capacity, time, and expertise to get all aspects of the balancing act just right. Instead, it seems wisest to look for opportunities for other institutions whether the federal courts, record labels, or artistic communities - to make discrete changes that improve the sample clearance system. That said, in this article we will focus exclusively on solutions related to non-infringing uses, specifically de minimis uses and fair uses.

One way to resolve some of the inefficiencies of the sample clearance system is to expand, codify, or otherwise clarify the set of non-infringing uses. These carve out a space for musicians who sample to use existing works without obtaining permission or paying a fee. For the uses that remain infringing, copyright holders' property rights are sharpened, generating some of the benefits described above. The benefits of clear legal rules can accrue, in other words, even when those who sample, rather than those who have been sampled, have an entitlement to use certain samples. The two main ways to delimit noninfringing uses are to set a de minimis threshold for copyright infringement and to treat some samples as fair use.

\section{A DE MINIMIS THRESHOLd FOR SOUND RECORDINGS}

As described in ch 4 of our book, ${ }^{2}$ the de minimis threshold in copyright law refers to the level below which courts deem the amount a musician takes from a copyrighted work too small to consider copyright infringement. (The Latin

\footnotetext{
${ }^{2}$ Ibid 222.
} 
phrase de minimis non curat lex means "the law does not concern itself with trifles".) Part of the motivation for the de minimis threshold is administrative the costs of litigation are too great to fight over tiny violations. But the de minimis threshold allows musicians a certain freedom to borrow small building blocks, like the three notes used by the Beastie Boys at issue in the Newton $v$ Diamond $^{3}$ decision in the United States. Limiting copyright protection to samples that reach a certain size helps prevent copyright from extending to ideas or concepts like a single note or a short phrase, when it is supposed to apply only to particular expressions of ideas. ${ }^{4}$

Decisions like Newton $v$ Diamond recognise a de minimis threshold for musical compositions. But the court in Bridgeport Music v Dimension Films ${ }^{5}$ reached the opposite conclusion with respect to sound recordings. That court held incorrectly, most scholars believe - that s 114(b) of the United States Copyright Code $^{6}$ foreclosed the possibility of applying a de minimis threshold to the infringement of sound recordings. The Bridgeport court read the section as an extension of sound recording copyright holders' rights to everything not explicitly reserved to the public. Yet s 114(b) is better understood as a limitation on rights with respect to sound recordings. ${ }^{7}$

The United States Congress could revise s 114(b) to clarify its meaning. One approach would involve setting a quantitative threshold for de minimis use, such as 'one second' or ' $1 \%$ of the length of the sampled recording'. Another approach is to allow the federal courts to determine the de minimis threshold on a case-by-case basis. Outside of the $6^{\text {th }}$ Circuit, courts need not follow the holding of Bridgeport and could restore a more defensible interpretation of s 114(b). The problem is that most cases never reach a judicial opinion; instead, parties tend to settle beforehand - largely because of the cost of copyright litigation, which is quite expensive. It is also an open question how much a future judicial opinion (say, the anti-Bridgeport) ${ }^{8}$ can affect licensing practices. Whether courts have traction in that regard would determine the relative appeal of focusing on them in any reform efforts. Another alternative is to require some de minimis threshold, but allow the music industry to determine the specifics.

\footnotetext{
${ }^{3} 349$ F 3d 591 (9 $9^{\text {th }}$ Cir, 2003).

${ }^{4}$ Copyright does not protect ideas. 17 USC $\S 102(b)$ (2006). See also Justin Hughes, 'Size Matters (or Should) in Copyright Law’ (2005) 74 Fordham Law Review 575, 617-18.

${ }^{5} 410$ F 3d 792 (6 $6^{\text {th }}$ Cir, 2005) ('Bridgeport').

${ }^{6} 17$ USC § 114 (2006).

7 'The exclusive right of the owner of copyright in a sound recording under clause (2) of section 106 is limited to the right to prepare a derivative work in which the actual sounds fixed in the sound recording are rearranged, remixed, or otherwise altered in sequence or quality': 17 USC § 114(b) (2006).

${ }^{8}$ Bridgeport, 410 F 3d $792\left(6^{\text {th }}\right.$ Cir, 2005).
} 
The absence of the de minimis rule for sound recordings has broad consequences. Without it, the de minimis rule for musical compositions becomes less meaningful for samplers, because most samples infringe both the sound recording and the musical composition copyrights in the sampled song. However implemented, a de minimis threshold should apply to the infringement of sound recordings to provide leeway in copyright law's balancing act between those who sample and those who have been sampled.

\section{DEFINING FaIR USE}

The largest and most important set of non-infringing uses falls under the fair use doctrine. Fair use is designed to protect freedom of expression, just as the 'fair dealing' body of law does in Canada, Britain, and many other Commonwealth countries. Law professor Terry Fisher says, 'The fair use doctrine, as its name suggests, is designed in the first instance to allow people to engage in activities though on their face would violate the copyright law, nevertheless seem on balance, fair' ${ }^{9}$ The fair use statute was written into the Copyright Act 1976 (US) to allow unauthorised uses of a copyrighted work for the purposes of education, criticism, and parody, among other things. Motion Picture Association of America attorney Dean Garfield elaborates: 'There are certain exceptions to the concepts of exclusivity which exist in the copyright - which is the predominant concept - there are concepts like fair use, which allow someone else to use a copyrighted work, as long as the use is fair.'

'And "fair" is really an equitable and balanced term', Garfield continues. 'If you are taking something that someone worked on and are transforming it in some significant way or if you are using it for educational purposes, then the lines that are drawn on the exclusive use of the copyright end there.' Some musicians develop a working understanding of the term. Gregg Gillis of Girl Talk told us, 'I understand fair use as having fairly strict criteria. Are you ripping people off? Are people buying your music instead of someone else's? Or is your music becoming something new and not negatively impacting the original artist? If so, then you can potentially use it without asking for permission.' Both Garfield's and Gillis's comments reflect the nature of fair use is a case-by-case determination with historical roots in equity. ${ }^{10}$

The United States' deeply rooted fair use legal tradition is relatively unique in the world, however, which means that its effectiveness is quite limited by geography (the fair dealing statutes in other countries arguably do not allow as many freedoms as fair use in the United States). Quite aptly, legal scholar

\footnotetext{
${ }^{9} 17$ USC § 107 (2006).

${ }^{10}$ For an early and influential decision, see Folsom v Marsh, 9 F Cas 342 (CCD Mass, 1841).
} 
Rosemary Coombe reminds us that fair use is 'a local ordinance in a global information economy'. We take this caveat seriously, although there is also no reason why fair use cannot be exported - just as we can look to other kinds of exceptions to copyright protection from foreign jurisdictions that could be imported.

Campbell v Acuff-Rose, ${ }^{11}$ a lawsuit pitting 2 Live Crew against Roy Orbison over the rap group's parody of Oh, Pretty Woman, set a very important precedent regarding fair use. Columbia Law professor Jane Ginsburg explains: 'In that parody case, the Supreme Court held - not as a descriptive matter, but as a normative matter - that there was no market for parody.' She explains that a licensing market for parodies 'does seem sort of counterintuitive. You don't really want the copyright owner to be able to control what people say about their work and whether people make fun of the work, including by copying some parts of the work in order to make fun of it'.

Nearly 10 years after that Supreme Court decision, Wu-Tang Clan member Ghostface Killah successfully claimed fair use for his marijuana-drenched parody of What a Wonderful World, popularised by Louis Armstrong. 'I see buds that are green/ red roses too/ I see the blunts for me and you', rapped Ghostface. Mr Armstrong probably would have thought this was funny - he was a notoriously heavy smoker of marijuana. ${ }^{12}$ Thus, it is well established that parody is within the core of fair use.

Although there is no hard and fast rule that allows us to instantly assess whether something is a fair use, the statute provides us with four factors to help us determine the legality of our borrowing. According to s 107 of the 1976 Copyright Act, ${ }^{13}$ this includes: '(1) the purpose and character of the use, including whether such use is of a commercial nature or is for nonprofit educational purposes; (2) the nature of the copyrighted work; (3) the amount and substantiality of the portion used in relation to the copyrighted work as a whole; (4) the effect of the use upon the potential market for or value of the copyrighted work'. ${ }^{14}$ In the 2 Live Crew case, a unanimous Supreme Court stated that these four factors should not be seen as a rigid checklist, where if you fail one of the four tests - a yes/no binary - your borrowing is illegal. Instead, the Court explained the four factors as existing on a continuum in which an overall balance of fairness is struck between the old work and new work. In

\footnotetext{
${ }^{11} 510$ US 569 (1994) ('Campbell').

12 Robert, 'Ghostface Killah Wins Copyright Infringement Case’ (27 October 2003) Rap News Network <http://www.rapnews.net/0-202-257646-00.html>.

1317 USC § 102(b) (2006).

1417 USC § 107 (2006).
} 
other words, it held that just because something is for profit does not disqualify it as fair use. ${ }^{15}$

Campbell also explained that the first factor asks 'whether and to what extent the new work is "transformative"' and that parody 'has an obvious claim to transformative value'. ${ }^{16}$ What Campbell suggested but did not resolve is how courts should decide which uses other than parody also qualify as 'transformative'. Jane Ginsburg explains:

[C]ourts have elaborated on that first factor to inquire if the use is 'transformative'. So in other words, are you just copying from the prior work so that you recycle it for pretty much the same thing as where you started, or are you doing something really creative, productive, giving new interpretation and so forth to what you've copied? In [the sampling] context, it's probably a good argument that the use is transformative - although that might depend on the nature of the sample, I don't know. And if, for example, I sample the bass guitar because I don't have a bass guitarist, and somehow this substitutes for a musician, that doesn't sound so transformative. But if I'm sampling because I'm weaving it in with other stuff or something like the Grey Album, there, I think you could make an argument that that's transformative.

Peter Jaszi suggests that the first fair use factor may favour a musician who sampled where 'the sample was substantially transformed. This would not be the drumbeat, necessarily, but it might be the vocal selection that was tweaked and modified and then inserted in a context different from the one in which it was originally used'. The notion of transformative use probably offers the most promising avenue for a significant number of samples to be considered fair use. Jaszi tells us that the concept of transformative use was not very well developed when sampling was emerging in the 1980s, but today it is universally established and understood.

The second fair use factor - the nature of the copyrighted work - seldom plays a role in sampling cases, but the third and fourth factors often do. The third factor asks courts to determine how much the sampling musician has taken, both quantitatively and qualitatively. Jane Ginsburg offers an illustration:

[T] he Grey Album, I think is an interesting example because it doesn't take too long before you get the joke, but it just keeps going and going and going - 'As My Guitar Gently Weeps' is the one I was thinking of [a sample taken from The Beatles' White Album]. And, of course, this is somewhat of a delicate operation because it is putting the court in the position of making what some might say is an artistic judgment. Who is the judge to decide

\footnotetext{
${ }^{15}$ Campbell, 510 US 569, 584-5 (1994).

${ }^{16}$ Ibid 579.
} 
whether you took more than you needed to take for your expressive purpose? But if the alternative is, 'I'm the artist, I'm the creator, and I decide how much I can take,' then all bets are off. That's completely self-serving, so you need some sort of standard. And so courts do tend to look fairly carefully at whether they think that the defendant has been gilding the lily.

In this way, the third factor injects much of the case-by-case subjectivity and unpredictability that characterises fair use analysis. The fourth factor, harm to the copyright holder's market, can loom large in the fair use analysis. With this factor, it matters to courts whether copyright holders are trying to license the use in question - whether they have set up shop to take advantage of the potential licensing revenue. If so, then the fair use claim might be weaker; if not, the fair use claim seems much stronger. Jane Ginsburg argues that because a market for sound recording sample licensing has already developed, this can cut against the fair use arguments of musicians who sample.

\section{COMmenting ON THE WORLD}

Fair use has an important role in preventing copyright from limiting freedom of speech. Terry Fisher explains ' $[\mathrm{t}] \mathrm{he}$ premier example here would probably be the dispute over the Wind Done Gone, which is a novel that, among other things, critically comments upon Gone With The Wind. In particular, it attacks its arguably racist dimensions'. He explains that after a good deal of litigation in that case, the Court of Appeals excused The Wind Done Gone from copyright infringement 'primarily on the ground that we want to afford room in modern culture for critical commentary'. ${ }^{17}$ Although this is a literary example, the same overall logic holds true for the sampling of, for instance, political speeches or news broadcasts for the purpose of parody or criticism. For instance, entertainment attorney Whitney Broussard argues that once public figures, entertainers, or politicians insert themselves into the popular culture - and put energy into being part of the public discourse - they are fair game for commentary.

One person who has engaged in just this sort of sampling is Matt Black of Coldcut. 'I think that our politicians are employed by the public and are fair game,' he says. 'Let's take Tony Blair, who said, “The lunatics have taken over the asylum”. He's a public figure; he's making that statement as a public figure in a public place, and I think that statement and that material is public property. I would argue that we are allowed to use that one to broadly fair use.' Black explains that collage can be a useful tool for political commentary because it enables one to take mass mediated messages and, as he puts it, 'freeze it,

${ }^{17}$ Suntrust Bank v Houghton Mifflin Co, 252 F 3d 1165 (11 ${ }^{\text {th }}$ Cir, 2001). 
analyze it, and build it back up again. We often say, the truth is in there, so if you actually take Bush's words and you rearrange them, then you can actually find out what he's really saying'.

Similarly, Public Enemy sampled the speeches of public figures. 'When we recorded It Takes a Nation and Fear of a Black Planet', Chuck D tells us, 'we used vocal samples from all over the place. We might use different TV samples and vocal samples from radio, or political speeches'. Founding Public Enemy member Hank Shocklee affirms this, saying, 'Public Enemy was not just a group that made hip-hop records that people can just dance to. It was also a source of information'. The 'golden age' records released by Public Enemy evoked and invoked - through the sampling of certain sounds, voices, and news broadcasts - the black power era of the late 1960s and early 1970s, all while also staying firmly rooted in the contemporary moment. 'What we wanted to create was kind of like a "reality record”,' Shocklee explains. 'You hear it out there on the streets, and now what you heard in the streets is now back in the record again.'

For instance, Fear of a Black Planet contained numerous samples of radio and television broadcasts about the group (and sometimes, as is the case with their song “Incident at 66.6 FM", Flavor Flav interrupting a call-in radio show that was critical of the group). 'We got so far into sampling, we even sampled ourselves, media coverage of ourselves. Our whole reason for doing music in the first place is because we wanted to sample from culture and put it back out there in the world.' Broussard says, 'I think that that kind of cultural back and forth is what culture's about — and the law should be very cautious about limiting that in any way, because you want that discourse'. Musician Tim Quirk adds, '[i]t's absolutely a free speech issue. And when the copyright law clashes with First Amendment law, First Amendment law has to win'. ${ }^{18}$

\section{FAIR USE IN THE MUSIC INDUSTRY}

In the United States music industry, fair use exists more in theory than in practice. 'Fair use is a misnomer', says Dina LaPolt, 'People start screaming, "Fair use, fair use, fair use”, but it's just a defense, which means you have to defend it'. Tim Quirk points out that you will get a different opinion about what fair use is, depending on whom you ask. 'If you ask a lawyer for a record company, which I have done - if you ask Cary Sherman, head of the RIAA [Recording Industry Association of America] - he will look you in the eye and say, "There is no such thing as fair use”. He will actually say that. And he will say, "It is nothing but a negative defense to a copyright infringement claim. It

\footnotetext{
${ }^{18}$ Referring to the United States Constitution amend I.
} 
doesn't exist absent a claim that you have done something wrong".' Many of those interviewed between 2005 and 2008 exhibited ignorance or indifference towards this legal doctrine. Take the following exchange, for instance:

Kembrew: 'Are you familiar with the legal doctrine of fair use?'

Eothan Alapatt: 'No'.

Another example:

Kembrew: 'Have you ever worked with an artist who sampled without permission under the belief that they were making fair use of a copyrighted material?'

Walter McDonough: ‘No’.

Dina LaPolt points to the example of Weird Al Yankovic, who people mistakenly assume invokes the fair use doctrine in his song parodies of Nirvana, Madonna, and others. 'I asked him myself, "Weird Al, do you get permission?" He says, "Always, always”, because he doesn't want to pay for defending his actions. He's got five kids. He doesn't want to pay some copyright lawyer a hundred grand to defend his fair use claim.' Bill Stafford used to license Weird Al's parodies when they were both employed by Arista Records. 'All of his items were indeed parody', Stafford says. 'And they would probably pass that [fair use] test. But no one wanted to find out. No one wanted to go down that road.' Whitney Broussard explains this cautious impulse, which leads to record companies and artists ignoring the possibilities that fair use allows. 'You know, fair use is a noble concept, but as a business strategy it's really, really weak', says Broussard. 'You really can't rely on that for business purposes. You really can't say, "Well, I'm going to jump into the gray area, here, and hope this works out okay". Some companies do that, but for larger companies that are big targets for lawsuits, it's rare that they would do that.'

Dina LaPolt summed up this perspective about fair use: 'It's a useless part of the Copyright Act. It should be just deleted. No one gets it.' Some of these dismissive attitudes stem from the fact that very few fair use cases involving music have ever been decided by a court, in part because of the cost of litigating a copyright infringement lawsuit. Andrew Bart says: 'The odds are astronomical that [a fair use] case will settle at some point before it goes to trial. That's why there are so few reported decisions. There's very little reason to be going all the way through the trial with all of the legal expense that it entails. As opposed to just trying to cut some sort of settlement.' Put bluntly, asserting fair use is a problematic business strategy. Copyright infringement suits could follow, which 
limits distribution opportunities - and presents potentially devastating costs (a quarter million dollars or much, much more) just to defend oneself.

\section{The Future of Fair Use: Proposals and Opinions}

Bridgeport ${ }^{19}$ not only created a bright line on the licensing front, but it also may have weakened fair use - despite the fact that the court made no explicit ruling on fair use in that case. Copyright infringement defendants, like any defendants, have to marshal all the legal defences they can. Without a de minimis threshold for sound recordings, sampler-defendants have to rely more heavily on fair use as an affirmative defence. But fair use, with its case-by-case, unpredictable nature, makes a better backstop than a baseball bat. Law professor Peter Jaszi emphasises that it is important not to give up on fair use, even in the nebulous world of digital sampling. He tells us that when the sampling system was forming 20 years ago, 'the two paths that were taken were the path of comprehensive licensing on the one hand - especially for artists with major label contracts - and the path of transgression on the other. The middle road, the road that considers the possibility that much of the sampling practice may in fact be perfectly okay under fair use, was not explored'.

Jaszi suggests that the music community could now develop a 'best practices' statement that defines the kinds of sampling it considers to be a fair use, which would necessarily involve a series of conversations among sampling artists. He explains:

Recent scholarship has established beyond doubt that courts - and other decision makers who care and who have roles in determining what is or isn't fair use - are influenced by the expressed consensus of various practice communities as to what is considered within those communities to be honest and reasonable dealing. So if a court wants to know if a given bit of quotation in a trade book is or isn't fair use, they look in other places for the standards and practices of the publishing community. And if the court wants to know whether a particular clip in a broadcast program is or isn't fair use, they look to the standards and practices of the broadcast community. This is an opportunity for artistic communities, should they choose to take it, to get involved - not only in responding to what lawyers may say about fair use, but to having a role in shaping the doctrine itself.

Commenting on the idea of a best practices statement involving sampling, Whitney Broussard observes, '[p]ersonally, I think that it would be a better system and you'd see more interesting art if the boundaries of fair use were (a) broadened and (b) clarified so that you could go into the studio and know that

${ }^{19} 410$ F $3 d 792$ (6 $6^{\text {th }}$ Cir, 2005). 
this is going to be fair use'. Despite the fact that someone like hip-hop producer El-P would like to see fair use expanded to embrace sampling and musical collage, he remains skeptical. Responding to Peter Jaszi's call for a music community-defined statement of best practices for sampling, El-P tells us:

I do want to point out that it is not going to happen because the musicians cannot talk to each other directly because we don't even own what we make. I've been in situations where I not only had permission to use something, but I became their friend and they were excited about the music, and I couldn't do it. I was going to put money in their pocket because I respected them. I went out of my way to contact them, to have a real conversation between two creative people ... The reason why none of this will ever happen is because the people who ultimately control it aren't really artists. It's the companies.

Jaszi responds by emphasising that even though artists do not own much of the music they create - at least on the sound recording front, which record companies tend to monopolise - this is still not a reason for musicians to not take charge of shaping the development of fair use. He argues, '[y]ou don't have to be a copyright owner in order to have strong aesthetic and ethical preferences for what is good and bad practices in sampling'. After the music community establishes what sampled uses would be fair, and not, the next step would be to see how courts respond to the question of whether digital sampling could be considered a fair use. Of course, this could very well happen before such a document is drafted.

Philo Farnsworth, who operates the Illegal Art label, which releases Girl Talk's albums, seems to be an obvious candidate for a lawsuit. To the surprise of many who have been following Girl Talk's brief career, there have been no lawsuits - despite the existence of hundreds of potential infringements of famous songs on each of his recent albums. Why no lawsuits? 'One reason may be that the mainstream music industry does not want to see a test case go to court', Farnsworth tells us. 'No one knows which side might win. As it now stands only a small number of artists will dare to release an album with uncleared samples. If a case weighed in our favor [sic], it would open the door for a multitude of artists to feel more comfortable about sampling without permission.' When asked if being sued would be a good thing for the art and law of sampling, Farnsworth responds, dryly, '[i]t would be good if we were able to win in court. It would be counterproductive if we lost'.

Some recent cases have also expanded fair use for collages that are deemed transformative. In 2006, the United States Court of Appeals of the $2^{\text {nd }}$ Circuit ruled on a case involving appropriation artist Jeff Koons and a photographer, 
Andrea Blanch. In Blanch $v$ Koons, ${ }^{20}$ the photographer's copyrighted image was incorporated into one of Koons's collages, titled Niagara. In creating this collage, Koons incorporated, and altered, Blanch's photograph that featured a woman's feet and legs - changing the colours, medium, size, details, and background on which the image was presented. The court ruled in Koons's favour, stating that its transformative nature made it a fair use. 'I think that the Jeff Koons Niagara case could be used as a model for non-parody appropriation in music', says Farnsworth. 'It seems that one of the key things courts look at in a fair use case is the fourth factor of fair use. That seems to weigh in our favor [sic], as it would be ridiculous to suggest that anyone was buying a Girl Talk album in place of buying one of the original sources he is sampling.'

'Even though fair use doesn't achieve the result of getting everyone paid, all the time', Peter Jaszi says, 'it may achieve the result of making it possible for artists to do the work they want to do'. Fair use can also reduce the kinds of economic inefficiencies that occur when new technologies emerge, which often complicate existing distribution or broadcast contracts, for instance. 'Fair use, where it applies, is independent of contracts', Jaszi points out. 'It overrides many, although not all contracts. Fair use, where it applies, is independent of platforms. It applies throughout the distribution system, without regard to the mode and nature of the distribution.'

In terms of legislative intervention, the United States Congress could reduce the uncertainty surrounding fair use. For instance, it could amend s 107 of the federal Copyright Code, which codifies the fair use doctrine, to clarify whether a sample-based song that is not a parody can qualify as a transformative use in at least some cases. Such a signal might spur various stakeholders in the music industry to work out a set of guidelines about which uses count as fair. The federal courts can also implement a clearer way to address fair use in sampling cases, perhaps including a workable definition of transformative uses for cases that do not involve parodies. Realistically, though, it is unlikely that Congress would, first, be motivated to alter the Copyright Code for the benefit of such a small class of constituents - remixers - and, secondly, there is no guarantee that the legislators would get it right. In fact, it is quite possible that they could make things worse by retooling the Code, especially given the lobbying power and influence of the entertainment industries that have Congress's ear.

\section{CONCLUSION}

Different approaches to reform should target distinct aspects of the problems in the sample clearance system. This article has focused exclusively on non-

${ }^{20} 467$ F $3 d 244$ (2 $\left.{ }^{\text {nd }} C i r, 2006\right)$. 
infringing uses, which applies primarily to musicians seeking to use multiple, brief samples per track, rather than longer, more recognisable samples from songs. Artists who make sample-heavy collages would benefit from both a de minimis threshold for sound recordings and a more established notion of transformative use under the fair use doctrine. However, this is merely a partial solution to the inefficiencies of the contemporary sample clearance system. The ideal reforms will alleviate the current system's restraints on artistic freedom while upholding musicians' or copyright holders' rights to compensation and control, when it is appropriate. Because the music industry is a creature of both copyright law and private industry, the best solution for the sample clearance system's shortcomings is a set of legal and business reforms that will complement each other. We recognise that this is no easy task, but we believe that reforms specifying an expanded range of non-infringing uses should be part of a comprehensive solution. 